\title{
Andalucía y el Mediterráneo: ¿Frontera Demográfica?
}

\author{
José Antonio NIETO CALMAESTRA*
}

\section{RESUMEN}

El Mediterráneo constituye un espacio geográfico, histórico, político y económico que, aunque ha venido perdiendo protagonismo, conserva una identidad de primera magnitud a escala mundial, pese a la inexistencia de cualquier tipo de proceso de integración de carácter supranacional.

En este contexto, se puede hablar de dos modelos demográficos: el de la orilla sur, que coincide con las fachadas asiática y africana, donde tras décadas de fuerte crecimiento de la población se ha iniciado una fase de moderación propiciada por el control de la mortalidad y la caída de la fecundidad; y el de la orilla europea, donde el crecimiento demográfico es mínimo, el proceso de envejecimiento acusado y la inmigración un fenómeno en auge. Entre ambos modelos, el Mediterráneo se erige en una línea de ruptura nítida sin parangón en cualquier otro ámbito mundial.

\section{ABSTRACT}

The Mediterranean is a geographical, historical, political and economic area which, despite its diminishing prominence and the non-existence of a supranational integration process, still retains a strong identity worldwide.

In this context, there are two demographic models: the Asian and African model of the Southern shores where, following decades of strong population growth, a phase to moderate the population growth has begun driven by the control of the mortality rate and a fall in the fertility rate; and the European model, where there is minimal

* Instituto de Cartografía de Andalucía 
population growth, a noticeable ageing process and where immigration is on the increase. The Mediterranean is located between the two models, on an dividing line, unlike anywhere else in the world.

\section{INTRODUCCIÓN.}

Cuna de civilizaciones, crisol de culturas, escenario de guerras e intercambios comerciales, el Mediterráneo constituye, y lo ha hecho desde la antigüedad, un espacio geográfico, histórico, político y económico, que aunque ha venido perdiendo protagonismo, conserva una identidad de primera magnitud a escala mundial, pese a la inexistencia de cualquier tipo de proceso de integración de carácter supranacional.

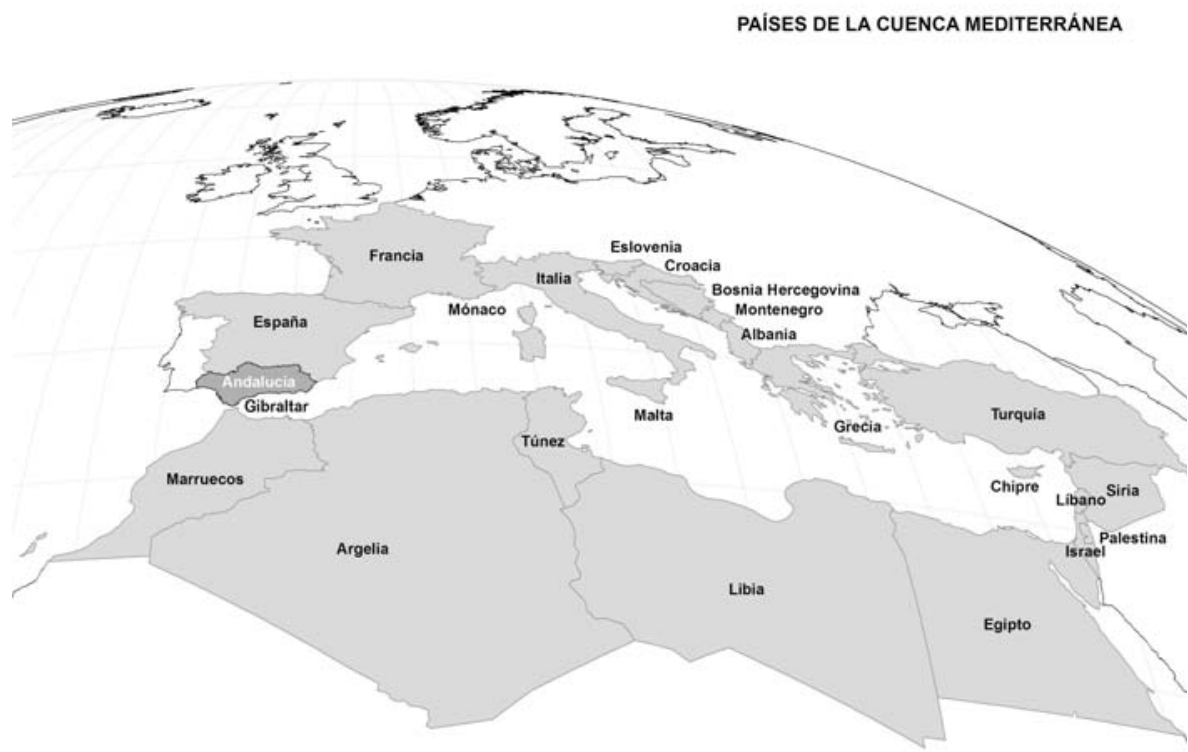

Actualmente, de Algeciras a Estambul, como dice la canción, se asoman a sus riberas una veintena de países pertenecientes a tres continentes que constituyen una amalgama de gran diversidad geográfica por cuanto la heterogeneidad en superficies, población, niveles de desarrollo, características sociales, económicas, culturales o religiosas son la nota dominante.

Las ilustraciones que aperecen en esta publicación en blanco y negro (para ahorrar costes de impresión) pueden verse en color en:

http://www.institucional.us.es/revistas/revistas/andaluces/htm/indice27.htm 
Poblacionalmente, y aún a riesgo de simplificar en demasía, se puede hablar de dos modelos demográficos, el de la orilla sur, que coincide con las fachadas asiática y africana, donde tras décadas de fuerte crecimiento de la población se ha iniciado una fase de moderación propiciada por el control de la mortalidad y la caída de la fecundidad; y el de la orilla europea, donde el crecimiento demográfico es mínimo, el proceso de envejecimiento acusado y la inmigración un fenómeno en auge. Entre ambos modelos, el Mediterráneo, pese al proceso de convergencia al que se tiende, se erige en una línea de ruptura nítida sin parangón en cualquier otro ámbito mundial.

Situada en el extremo occidental norteño, Andalucía, que siempre ha sido lugar de paso y puente entre las dos orillas, se integra plenamente, como tendremos ocasión de comprobar, en el modelo europeo, al que se incorpora tras un rápido y a veces vertiginoso proceso de convergencia.

\section{UN BREVE APUNTE METODOLÓGICO ANTES DE COMENZAR.}

Una de las mayores dificultades de cualquier estudio sobre población y más si, como es el caso, se pretende comparar lo que ocurre en distintos países o ámbitos geográficos, reside en la disponibilidad de fuentes estadísticas y documentales que permitan abordarlo con éxito, cuestión que, pese a lo que en principio pudiera parecer, no siempre es fácil pues la calidad de los datos, que publican los distintos organismos estadísticos de cada país, deja mucho que desear pues, como afirma R. Puyol (2003), los censos "subestiman la información real" y "la información de los sucesos vitales, ni resulta completa, ni es suficientemente precisa, ni está adecuadamente desagregada".

Frecuentemente, problemas como: la diferente finalidad de la producción estadística, el uso de metodologías de elaboración y conceptualizaciones distintas, la falta de homogeneidad en las fechas de referencia etc. dificultan la comparabilidad y exigen un trabajo previo de armonización que, dependiendo de la escala de estudio, muchas veces no es posible abordar. 
En este caso, y dado la imposibilidad de utilizar la producción estadística de cada país, se han tomado como referencia bases de datos y recopilaciones estadísticas hechas, con diferente objeto, por diferentes organismos internacionales, caso del Cuadro de la Población Mundial que anualmente publica el Population Reference Bureau (www.prb.org), la recopilación estadística ofrecida por el Banco de Datos de Información sobre Población de las Naciones Unidas (www.un.org/spanish/ popin) o el World Gazetteer (www.population-statistics.com).

Estas fuentes nos han facilitado la información necesaria para aproximarnos a la realidad demográfica actual de los países ribereños y de los subámbitos establecidos. De igual forma, nos han permitido una aproximación evolutiva a los fenómenos y poder completar la panorámica con proyecciones ${ }^{1}$ a medio-largo plazo, lo cual no deja de tener su interés.

Aunque el uso de estas fuentes nos garantiza la homogeneidad para los datos referentes a cada país, el introducir la escala regional, con la particular referencia al caso andaluz, nos ha exigido ampliar el repertorio estadístico y documental para intentar obtener para Andalucía una réplica de la información (datos, proyecciones, etc) con la que contábamos para los distintos países, labor que no siempre ha sido posible ${ }^{2}$.

Este mismo esfuerzo ha requerido el intento de poner en evidencia la brecha demográfica existente entre norte y sur mediante el ejemplo comparativo de los casos andaluz y rifeño para el que ha sido imprescindible acudir a las bases de datos de los organismos estadísticos de España y Marruecos para aportar una perspectiva poco frecuente por las enormes dificultades existentes para la armonización de la información. La más evidente de ellas, la distinta fecha de referencia temporal de los datos, pues mientras los correspondientes a Marruecos se refieren a 2004, fecha de realización del último recuento poblacional hecho en el país vecino, los de España proceden del Censo de 2001.

\footnotetext{
${ }^{1}$ De los diferentes escenarios de proyección se ha tomado siempre como referencia la hipótesis media que, dado la gran incertidumbre que rodea a los hechos demográficos, nos parece la menos arriesgada.

${ }^{2}$ La tarea ha sido especialmente complicada al trabajar con las proyecciones pues ni establecían escenarios temporales comunes, ni utilizaban los mismos indicadores de referencia.
} 


\section{PESO DEMOGRÁFICO Y TAMAÑO POBLACIONAL.}

El volumen poblacional de los países ribereños del Mediterráneo se acerca en la actualidad a los 457 millones de habitantes que suponen algo menos del $7 \%$ del conjunto de la población mundial, sobre el que se aprecia una progresiva pérdida de protagonismo pues a mediados del siglo XX este porcentaje se situaba sobre el $8 \%$ mientras en 2050 se estima que apenas supere el $6 \%$.

Gráfico 1. Significación de la población de la Cuenca mediterránea en la población mundial

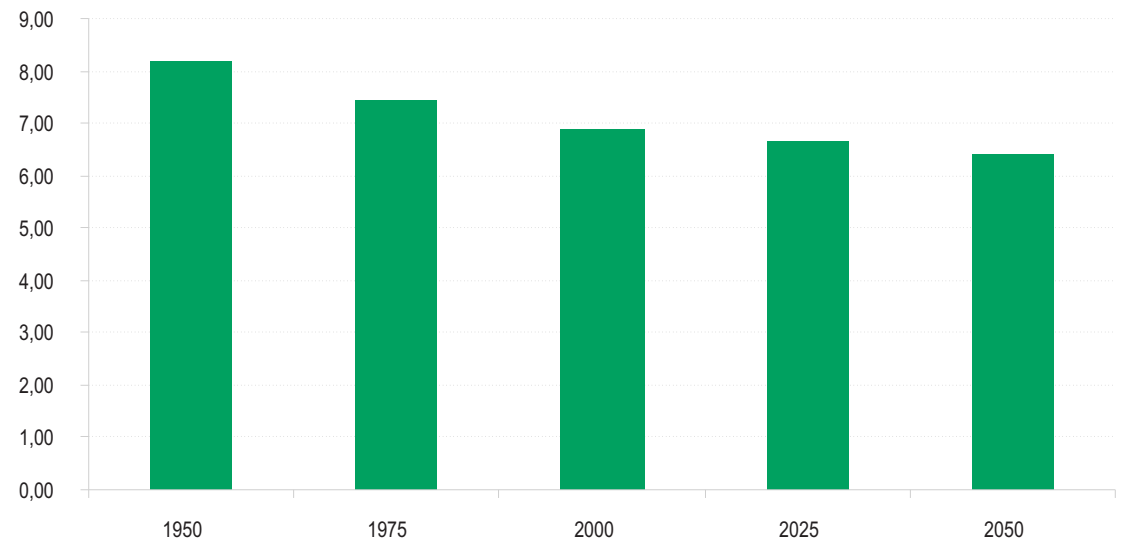

Fuente: Naciones Unidas. Banco de datos de información sobre población.

De forma paralela se ha hecho patente otro fenómeno, el vuelco en el peso demográfico de las orillas, así si en 1950 el flanco europeo suponía en torno al 65\% de la población total de la cuenca, hoy día apenas significa un $42 \%$, con una clara tendencia a la baja pues en 2050 apenas supondrá un 33\% del total de efectivos.

Este vuelco del centro de gravedad demográfico ha hecho que países del flanco norte como Italia o Francia, que en los cincuenta del siglo pasado eran, con diferencia, los más poblados del ámbito mediterráneo, hayan cedido el testigo a Turquía y Egipto, ambos en la orilla sur. 
Gráfico 2. Evolución de la población en la Cuenca mediterránea

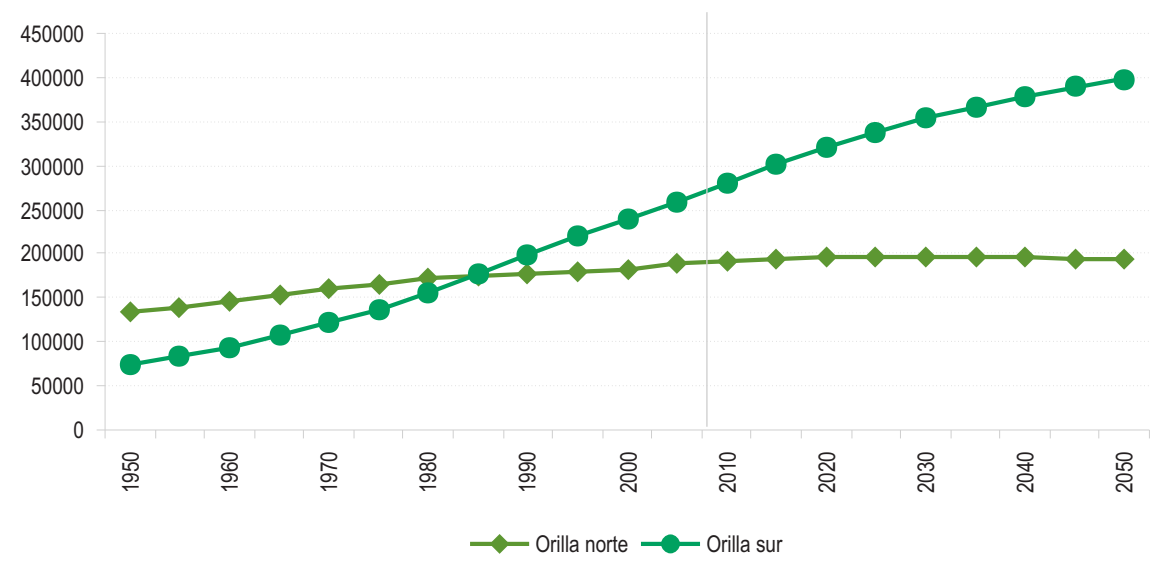

Precisamente otra característica propia de la demografía de la zona es la coexistencia y el contraste entre gigantes poblacionales del calibre de Turquía o Egipto, que superan los 70 millones de habitantes y ocupan, respectivamente, los puestos 16 y 17 del ranking mundial y la presencia de microestados demográficos que apenas cuentan con unos miles de habitantes (Gibraltar, Mónaco, Malta, Montenegro, Chipre, etc). En este contexto Andalucía, con unos 8 millones de habitantes, se posiciona en una escala intermedia por encima de países como Israel, Libia, Croacia o Líbano y se acerca al tamaño poblacional de estados como Túnez o Grecia.

Gráfico 3. Tamaño demográfico de los países de la Cuenca mediterránea

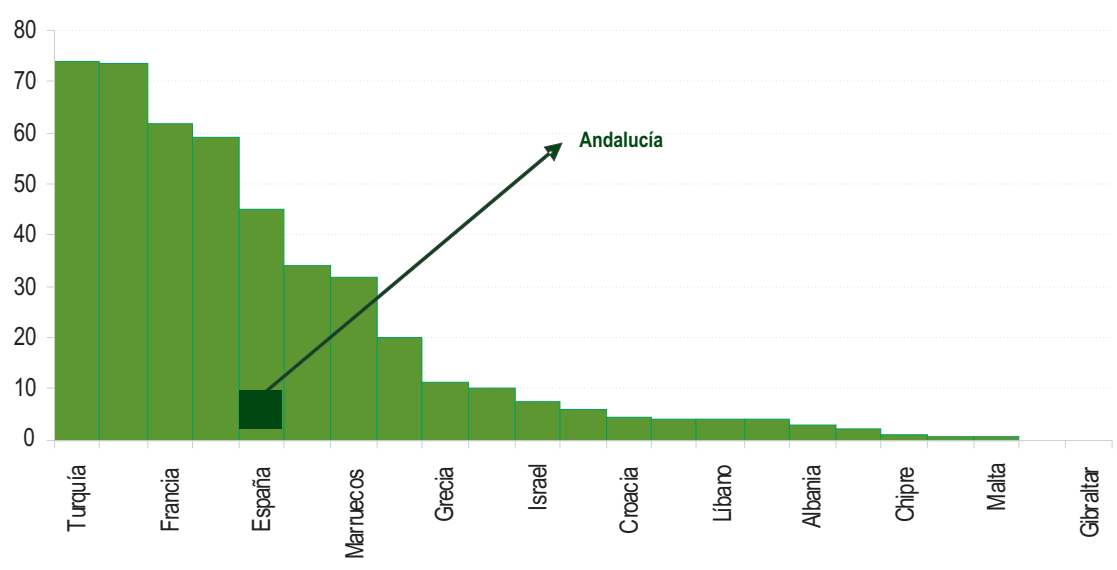

Fuente: UNFPA Cuadro de la población mundial, 2007. 


\section{DISTRIBUCIÓN DE LA POBLACIÓN.}

Aunque los valores medios nacionales de densidad de población enmascaran los notables desequilibrios que caracterizan la distribución geográfica de la población en los países de la cuenca mediterránea, dado la coexistencia de zonas sobresaturadas con verdaderos desiertos demográficos, son indicativos de los contrastes que enfrentan a países como Libia que apenas alcanza los $10 \mathrm{~h} / \mathrm{Km}^{2}$ con otros como Malta, Palestina, Líbano o Israel donde se superan los 250.

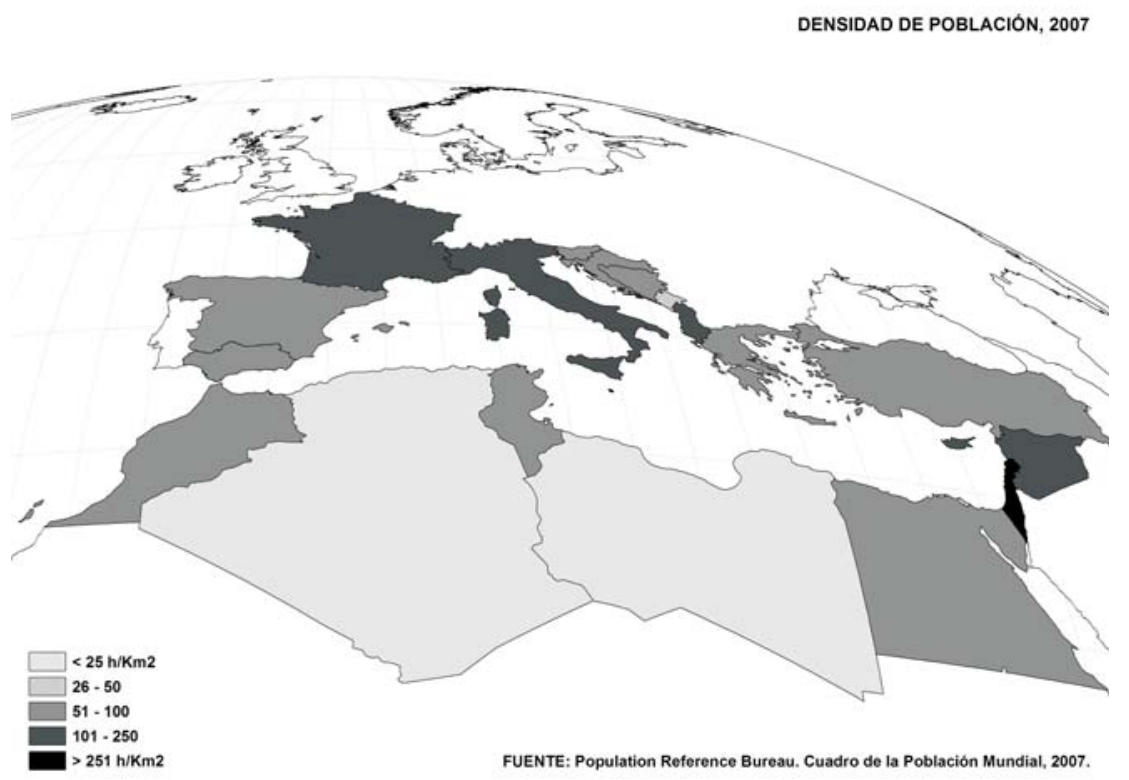

Una vez más, Andalucía con unos $90 \mathrm{~h} / \mathrm{Km} 2$ se posiciona en un puesto intermedio, aunque, dentro de ella, también se observan estos desequilibrios en la distribución de la población.

Algo común a toda la cuenca es el creciente protagonismo adquirido por dos fenómenos que caracterizan la distribución de la población en la zona el proceso de litoralización de los efectivos y la constatación de un imparable crecimiento urbanístico. 


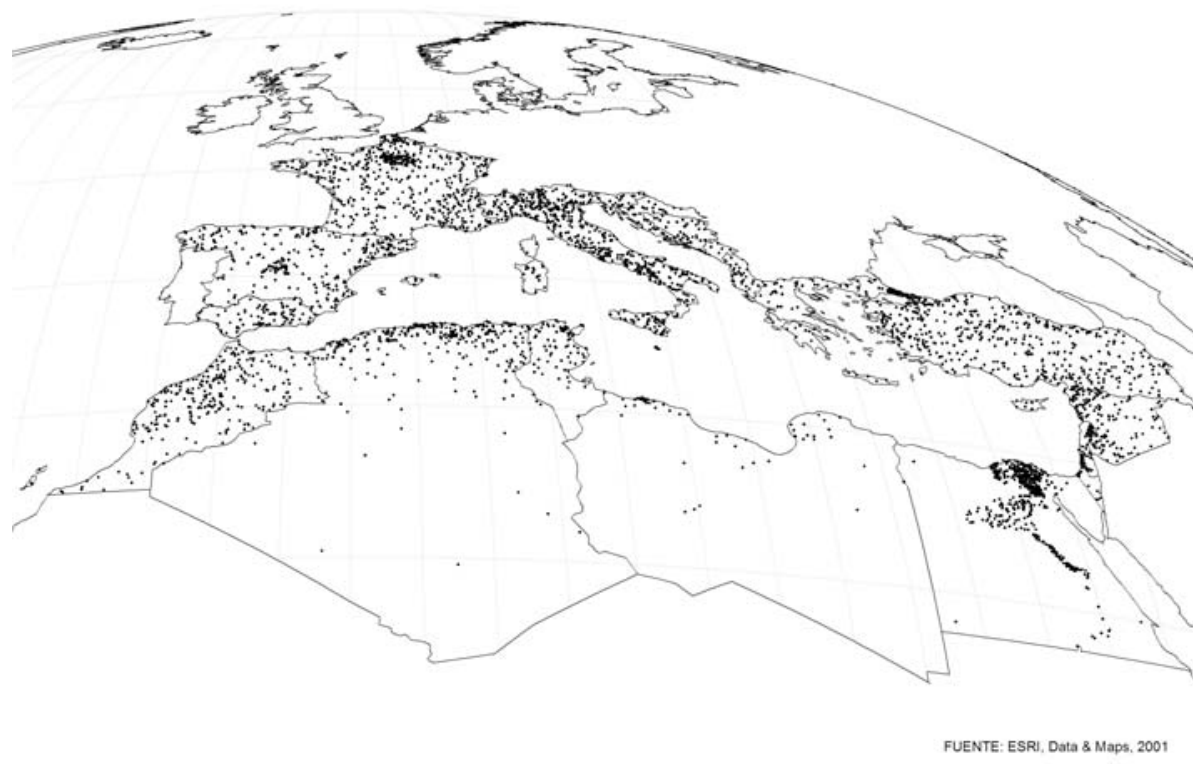

Así, mientras la población de la zona costera mediterránea, en la que tienen un papel destacado algunos valles fluviales como el del Nilo o el del Po, se ha multiplicado por dos desde 1950 pasando de los 72 a los 156 millones de habitantes actuales, la población urbana lo ha hecho por tres.

En este sentido la cuenca mediterránea, que siempre ha destacado como una zona de alto grado de urbanización, se confirma como un área fuertemente urbanizada pues, actualmente, algo más del $66,3 \%$ de sus efectivos reside en ciudades, situación que, sobretodo en la orilla sur, genera graves desequilibrios por los marcados contrastes entre lo urbano y lo rural. 


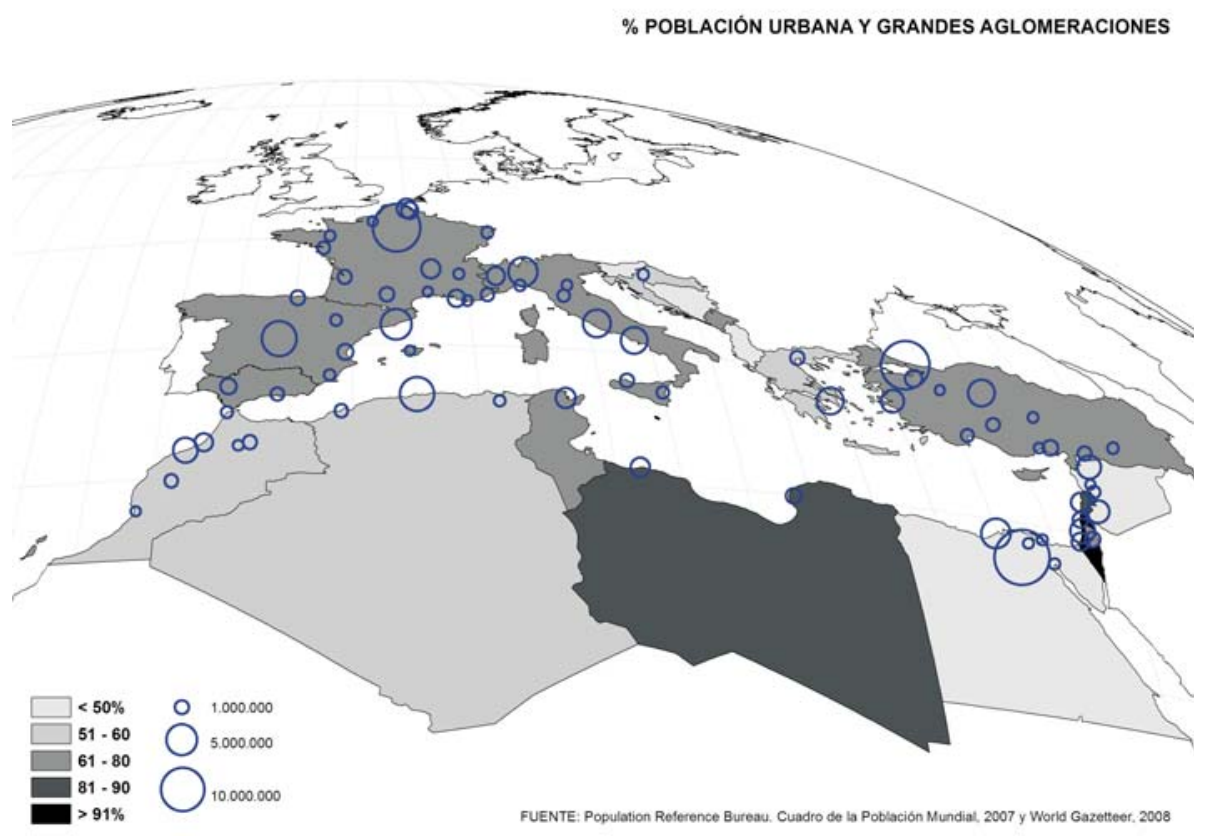

Consecuencia de este desaforado crecimiento de lo urbano es el surgimiento y consolidación de grandes aglomeraciones urbanas (76 de más de 500.000 h en 2008 según el World Gazetter), algunas de rango mundial, en las que se asientan millones de personas caso de Estambul (12,2 millones de habitantes), Argel (6,3), Barcelona (5), Alejandría $(4,5)$, Roma $(3,9)$ o Atenas $(3,8)$ que, en primera línea de costa, refuerzan el papel de otras metrópolis como El Cairo $(16,1)$, París $(11,8)$, Madrid $(6,3)$ o Milán $(4,5)$ situadas algo más al interior.

Tanto el proceso de litoralización, como el creciente fenómeno urbano, tienen su reflejo en Andalucía que en las últimas décadas ha sido testigo de un trasvase poblacional sin precedentes que ha mermado el interior de la región y las zonas rurales favoreciendo a la franja costera y a las grandes ciudades y a sus entornos inmediatos. Así de 1950 a nuestros días, la población en núcleos mayores de 10.000 habitantes ha pasado del $52,82 \%$ al $78,61 \%$ de los efectivos de la región, y la del cordón de municipios litorales que en 1950 apenas significaba el 20,22\%, hoy supone el $34,42 \%$. 
En paralelo, aunque evidentemente a otra escala, se constata, de igual forma, la conformación de pequeñas aglomeraciones urbanas caso de las de Almería, Huelva, Cádiz-Jerez, Algeciras y Málaga en el litoral y las de Granada, Jaén, Córdoba y Sevilla, que es la mayor de todas (1,5 millones de habitantes), en el interior.

\section{LA DINÁMICA DEMOGRÁFICA.}

La evolución de los distintos componentes de la dinámica demográfica revela, al menos, una doble realidad en los países de la cuenca mediterránea, pues mientras la componente natural, aunque en distintas fases en una y otra orilla, muestra una tendencia similar, las migraciones dibujan un panorama diferente pues los flujos sur-norte, que son los predominantes, para nada son comparables con los que se producen en sentido contrario, poniendo de manifiesto otra de las "fronteras" existentes entre ambas riberas, la fractura económica.

El primer aspecto que vamos a tratar, para analizar la dinámica demográfica de la cuenca mediterránea, es el crecimiento de la población. Viendo su evolución se aprecia una tendencia generalizada a la baja que, sin embargo, desde el punto de vista geográfico, hay que matizar pues los puntos de partida y llegada en una y otra orilla no son los mismos.

Gráfico 4. Evolución del crecimiento demográfico en la Cuenca mediterránea

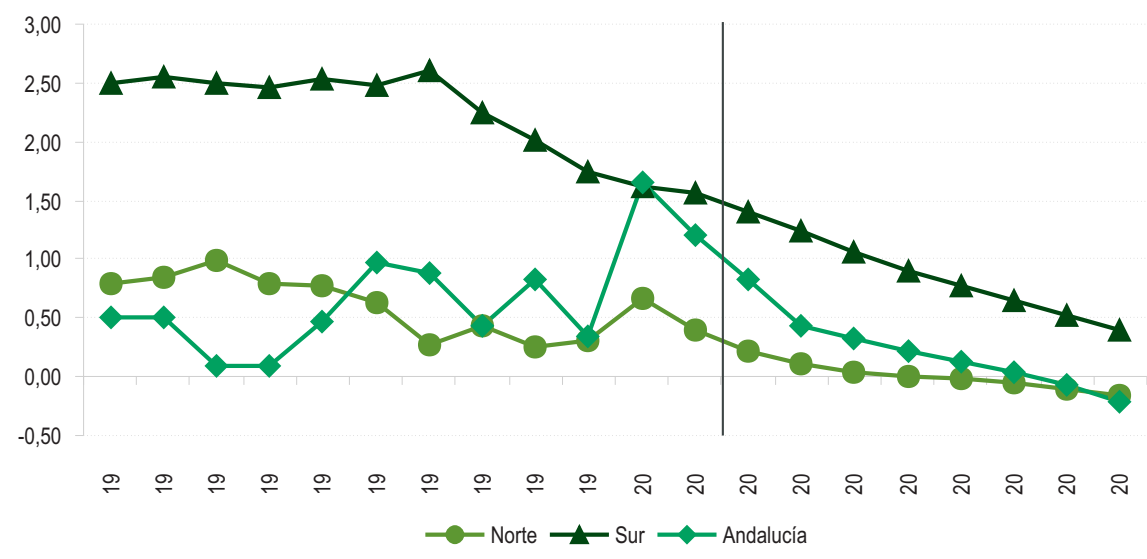

Fuente: Naciones Unidas. Banco de datos de información sobre población. 
Así, mientras en el flanco europeo se parte de crecimientos medios anuales inferiores al $1 \%{ }^{3}$ en el primer lustro de los cincuenta, en la fachada sur el crecimiento se situaba por encima del 2,5\%. A partir de ahí el retroceso en el crecimiento es palpable en toda la cuenca aunque en el caso europeo es tan titubeante que casi se podría hablar de estancamiento pues actualmente, tras una leve recuperación, debida a la incidencia de la inmigración, los valores se sitúan prácticamente al mismo nivel que a mediados del siglo pasado.

No ocurre lo mismo en la orilla sur donde las tasas medias anuales se sitúan actualmente en torno al 1,7\%, prácticamente el doble que en el sector europeo, pero casi la mitad del crecimiento de mediados de siglo XX.

Gráfico 5. Evolución del crecimiento demográfico en la Cuenca mediterránea por países

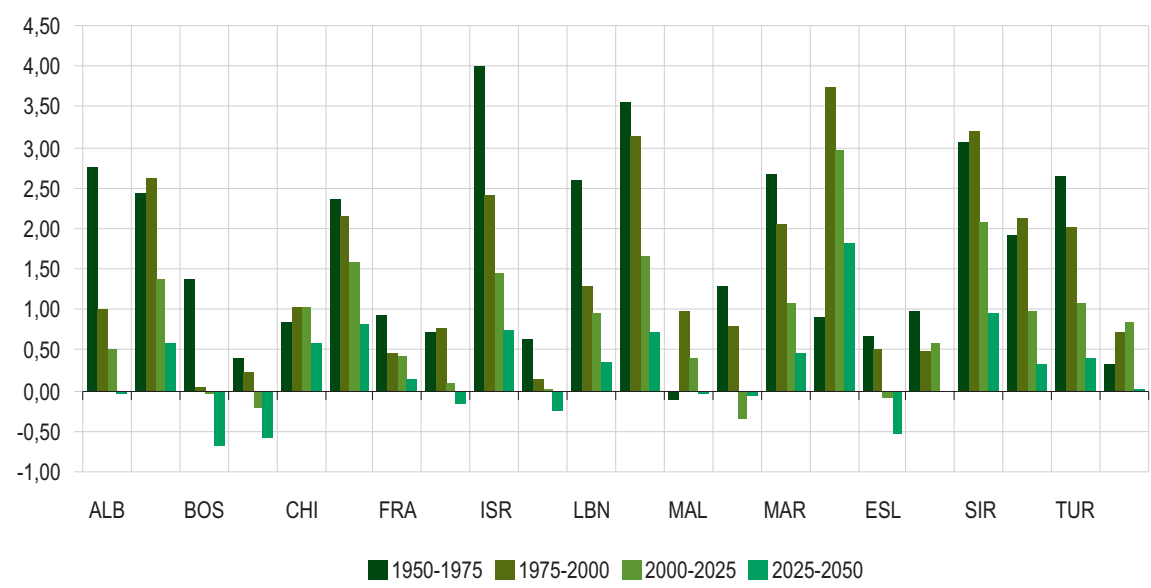

Fuente: Naciones Unidas. Banco de datos de información sobre población.

La situación por países, como se puede apreciar en el gráfico de una forma más sintética, es de lo más variopinta situándose entre los estadosc de máximo crecimiento algunos como Israel, Palestina, Libia o Siria, donde el elemento población

\footnotetext{
${ }^{3}$ Crecimientos del $1 \%$ anual implican un tiempo de duplicación del número de efectivos del orden de unos 70 años (Buccianti), periodo del que queda muy lejos la orilla europea y que se reduce en más de la mitad en el sur.
} 
no está exento de matices geoestratégicos, hasta el punto de que, en conflictos como el palestino-israelí, se ha llegado a acuñar el concepto de "bomba demográfica"4.

Frente a ellos, países como Bosnia, Croacia, Montenegro, Eslovaquia, en buena medida por las secuelas de la crisis de los Balcanes, u otros como Grecia o Italia, presentan crecimientos mucho menores y tendencia al antes comentado decrecimiento demográfico.

La previsión es que el retroceso de las tasas de crecimiento continúe en ambas orillas aunque con una notable diferencia pues mientras en el flanco afroasiático se prevén valores del orden del $0,5 \%$ medio anual, a mediados del presente siglo, en el europeo los promedios a medio plazo (2025) empezarán a negativizarse en breve con la consecuente merma demográfica.

En este contexto Andalucía, aunque nunca ha tenido un crecimiento real negativo, se ha visto afectada por procesos como el éxodo rural de las décadas de los 50-60 del pasado siglo, o por el más reciente retroceso de la fecundidad, factores que han determinado que los niveles de crecimiento no hayan sido nunca muy elevados. Pese a ello, y más aún si se mantienen las actuales corrientes migratorias que, como se puede apreciar acentúan considerablemente el aumento de efectivos en los primeros años del presente siglo, la previsión es que el crecimiento futuro siga teniendo signo positivo, al menos hasta la década de los cuarenta del siglo XXI.

Uno de los factores claves en el retroceso del crecimiento es la caída de la natalidad, rasgo común a toda la cuenca aunque se mantenga un claro diferencial entre el norte y el sur, pues mientras en el lado europeo las tasas brutas medias anuales apenas alcanzan el 10-11 por mil en muchos países, en el resto de la cuenca, salvo en algún que otro caso puntual, como Túnez o Chipre, sitúan su promedio en torno al 20 por mil cuando no sobre él ya que Siria o Egipto, por ejemplo, registran más de 25 nacidos por cada mil habitantes y los Territorios Ocupados de Palestina más de 33 .

\footnotetext{
${ }^{4}$ En este caso concreto, se alude con esta terminología a la mayor capacidad de crecimiento demográfico de la población árabe y al peligro que ello puede suponer para el colectivo judío en un territorio exiguo, como Israel, que está rodeado de países de religión musulmana.
} 


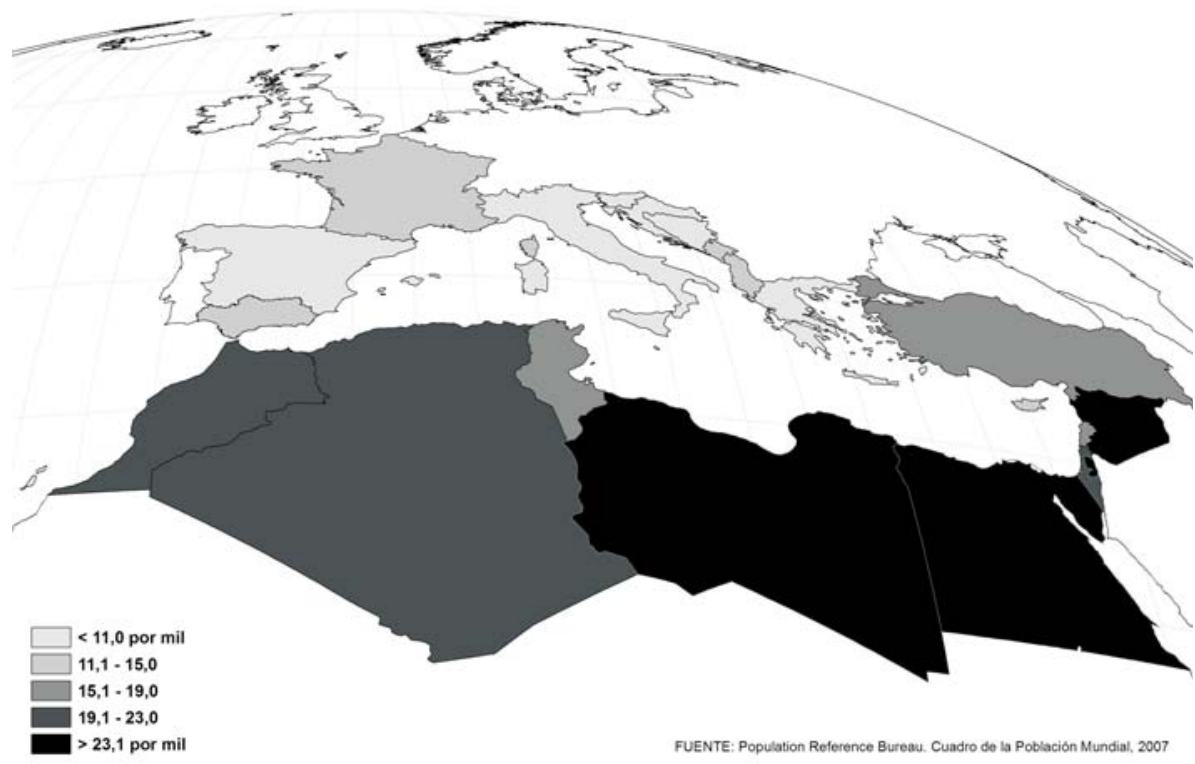

En Andalucía las Tasas Brutas de Natalidad se sitúan en torno al 11,6 por mil en consonancia con los valores registrados en la orilla norte.

Entre las causas de este retroceso natalicio están el retraso en la edad matrimonial, que ha provocado una reducción del periodo de vida fértil, los cambios sociales y culturales acontecidos en las últimas décadas que, aunque con menor ímpetu, también han caldo en la orilla sur, la diferente concepción de las familias y el auge de la contracepción (planificación familiar, anticonceptivos). El resultado es una caída, sin precedentes, de la fecundidad que en el lado europeo, después de haberse bajado de los niveles de reemplazo (2,1 hijos por mujer) y haberse tocado fondo con mínimos históricos hace unos años, ha empezado a notarse una tímida recuperación. 
Gráfico 6. Evolución del Índice Sintético de Fecundidad en la Cuenca mediterránea

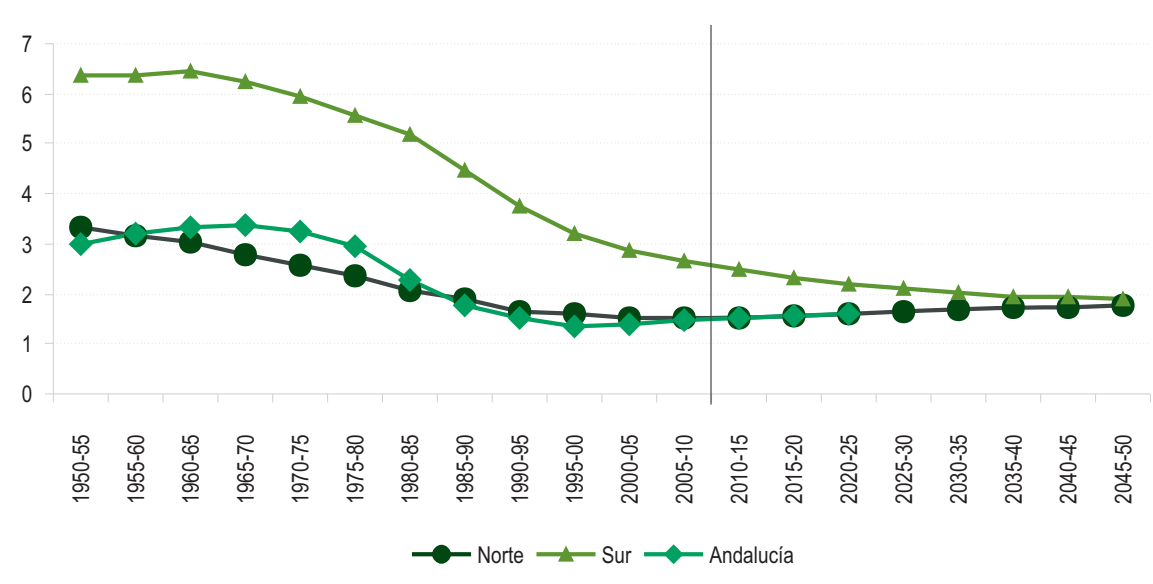

Fuente: Naciones Unidas. Banco de datos de información sobre población.

Pese al retroceso generalizado en toda la cuenca, el contraste con la orilla sur es manifiesto pues en la mayoría de países del sur el promedio se sitúa entre los 2 y los 4 hijos por mujer, aunque en casos como Palestina la ratio es superior a los 5 .

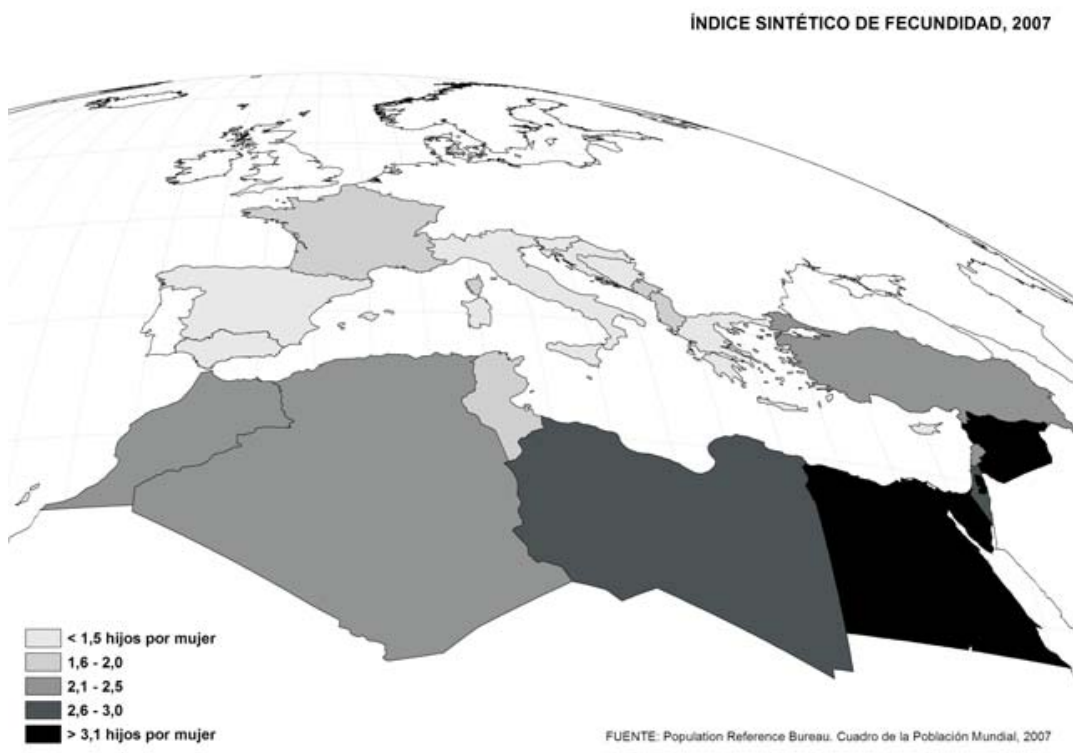


En este caso, lo acontecido en Andalucía no difiere demasiado de lo ocurrido en el resto del lado europeo pues actualmente el índice sintético de fecundidad, que está en torno a los 1,44 hijos por mujer, esta iniciando una pequeña recuperación tras años de caída continúa.

Por lo que respecta a la mortalidad, a grandes rasgos habría que subrayar un notable retroceso debido básicamente a la progresiva mejora de las condiciones higiénico-sanitarias, al control/erradicación de las crisis epidémicas que con carácter cíclico aún afectaban a algunos países de la zona y al éxito de la implantación de campañas de vacunación contra distintas enfermedades.

TASAS BRUTAS DE MORTALIDAD, 2007

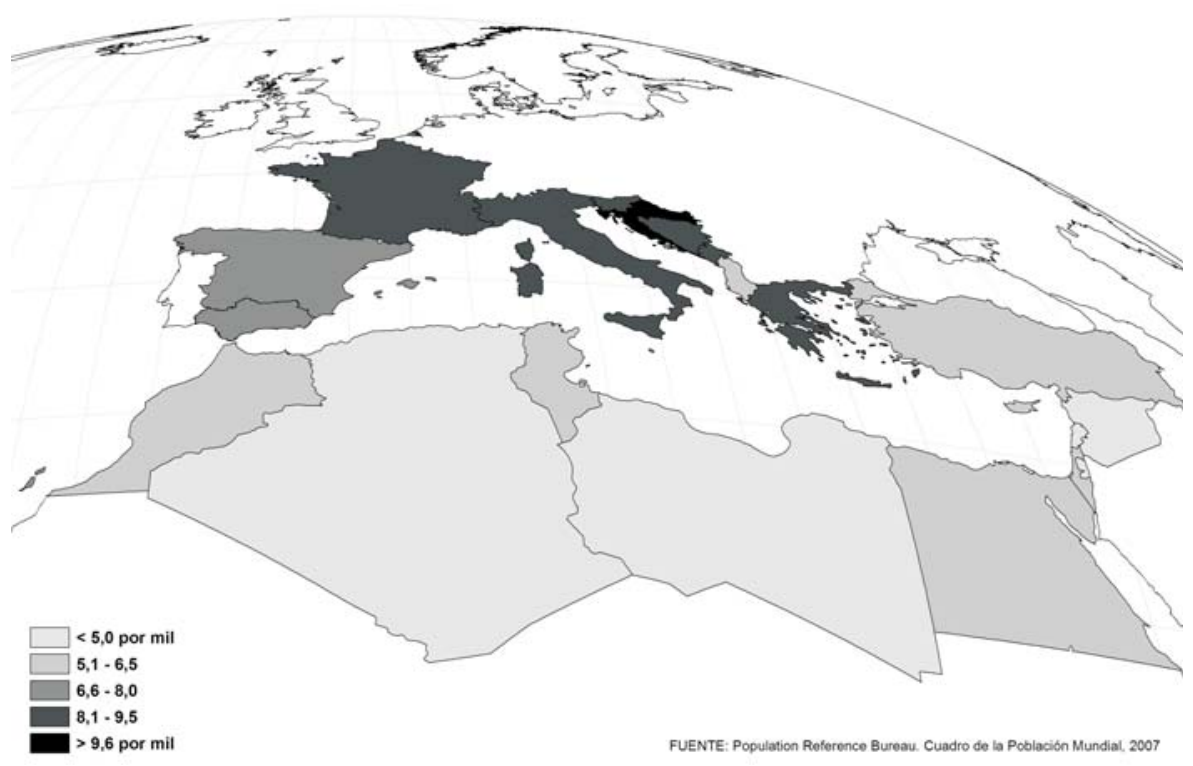

Una vez más, la contraposición entre una orilla europea, donde los niveles de envejecimiento hacen repuntar las tasas de mortalidad, contrasta con la sur donde el retroceso es la pauta general siendo la principal causa del mismo el acusado declive de la mortalidad infantil, en la que dejan de primar los factores exógenos, tan frecuentes en países de regímenes demográficos poco evolucionados, para adquirir mayor relevancia los decesos debidos a causas endógenas. 
Una vez más, la disimetría entre un lado y otro, al respecto de la mortalidad infantil, es manifiesta. Incluso en la orilla europea se podría diferenciar entre el sector occidental, donde estaría Andalucía (4,4 por mil) y habría que incluir a Grecia y Eslovenia, con valores, que se sitúan por debajo de los 4 óbitos por cada mil nacidos, y el sector balcánico (Croacia, Montenegro, Bosnia, Albania) donde los niveles son algo más elevados (6-9 por mil) y aún pueden retroceder. Los márgenes de reducción son mucho mayores en la orilla sur, especialmente en Marruecos, Egipto o Argelia, donde las tasas se sitúan sobre los 30 fallecidos menores de un año por cada mil nacidos.

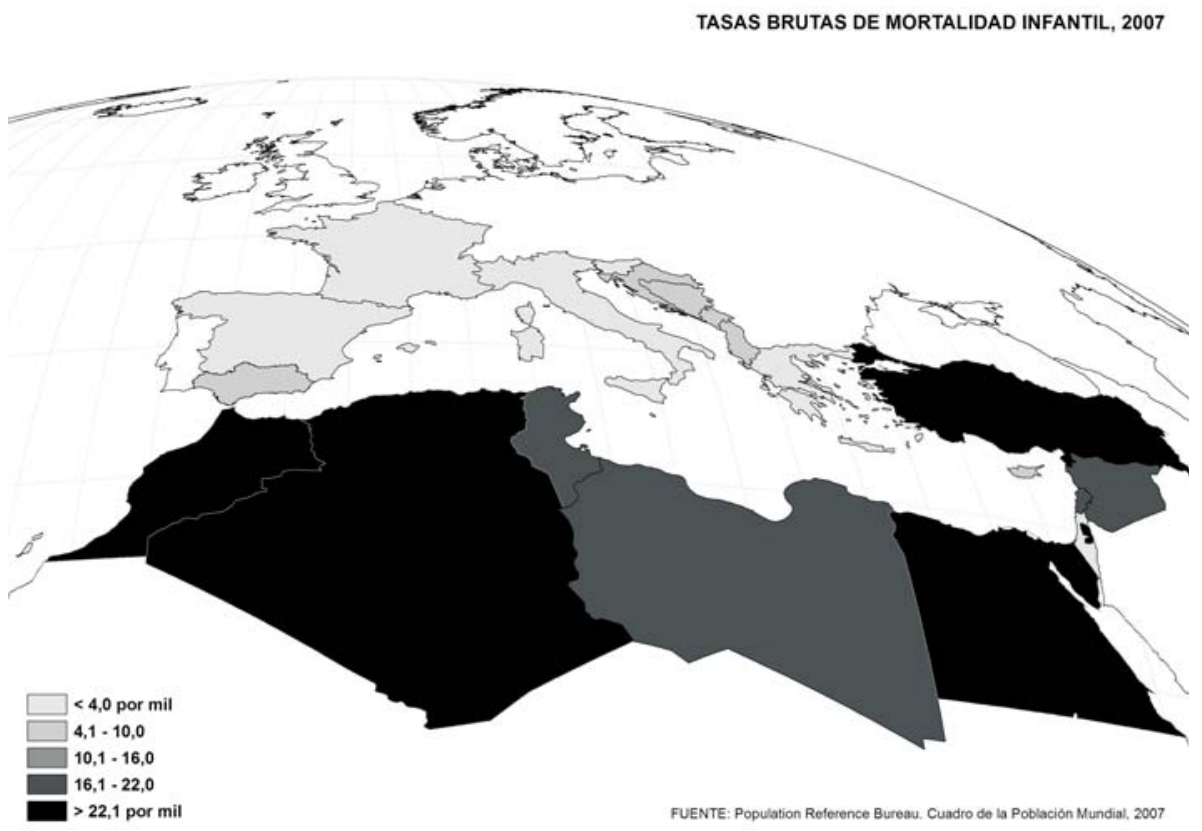

Pese a las diferencias que aún se observan, la tendencia a la convergencia futura de este indicador en ambas orillas es clara pues los valores del sector meridional terminarán, a medio-largo plazo, por acercarse a los niveles europeos que prácticamente están en el mínimo posible. 
Gráfico 7. Evolución de las Tasas de Mortalidad Infantil en la Cuenca mediterránea

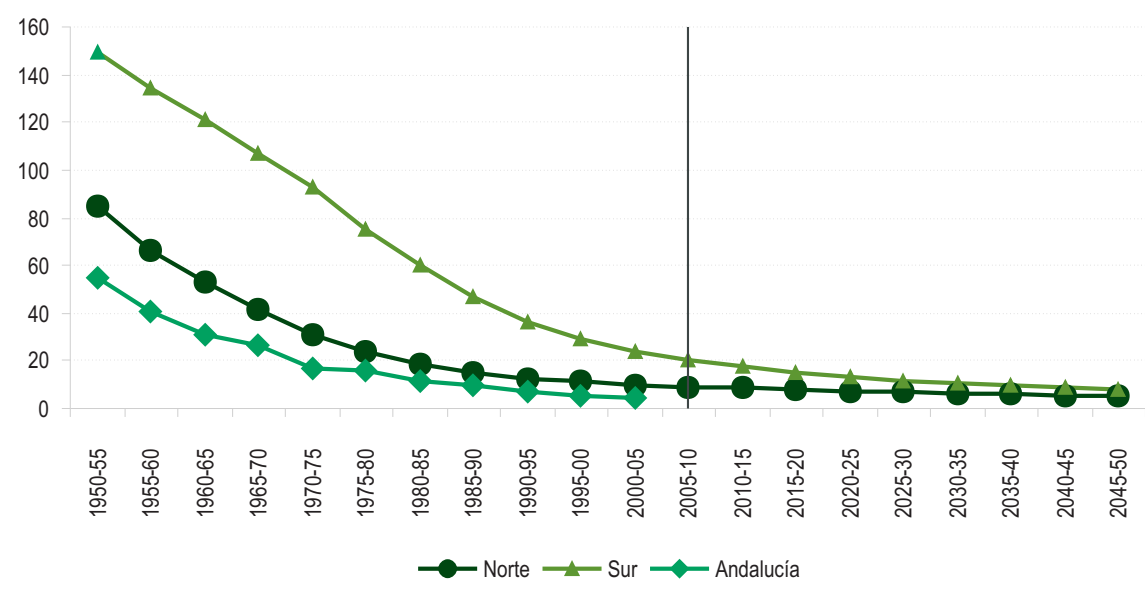

Fuente: Naciones Unidas. Banco de datos de información sobre población.

El retroceso de la mortalidad infantil registrado en las últimas décadas se traduce en un notable avance de la esperanza de vida que, en el peor de los casos, se sitúa por encima de los 70 años para el conjunto de la población cuando hace apenas unas décadas no llegaba a los 60.

Gráfico 8. Evolución de la Esperanza de Vida al Nacer en la Cuenca mediterránea

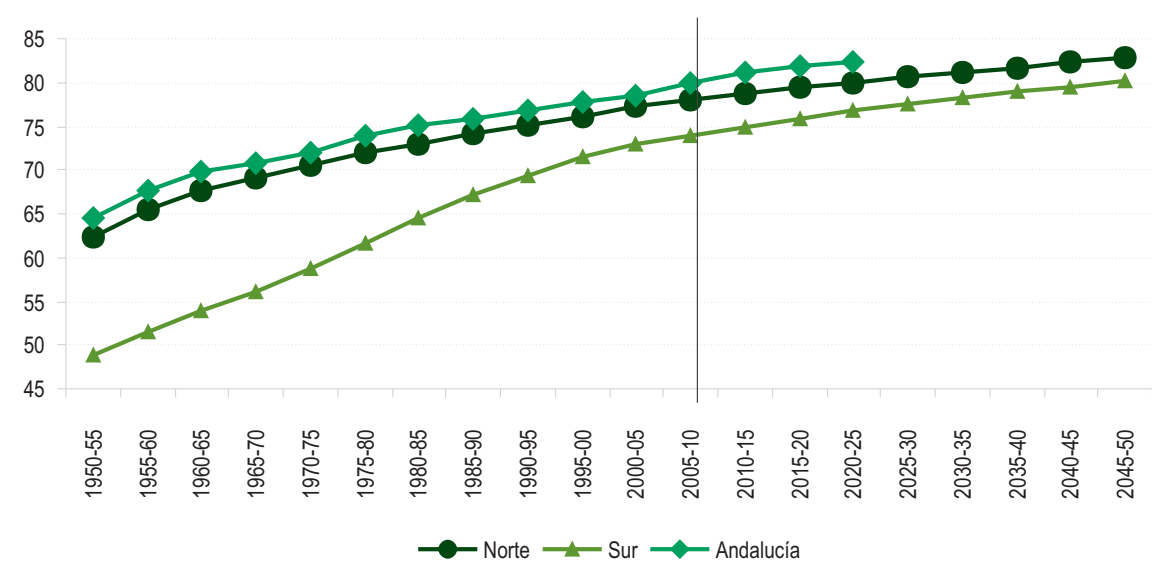

Fuente: Naciones Unidas. Banco de datos de información sobre población. 
Una vez más, la oposición norte-sur, pese a contadas excepciones como Israel o Chipre, está patente localizándose en la orilla europea alguno de los países (Francia, Italia, España) con mayor esperanza de vida del mundo. Andalucía, donde la esperanza de vida al nacer se sitúa en los 76 años para los varones y en los 82 para las mujeres, puede ser otro buen ejemplo de ello.

En el flanco meridional, Marruecos, Líbano o Egipto, detentan la menor esperanza de vida de la cuenca pues los promedios del indicador apenas se sitúan en torno a los 70-71 años para el conjunto de la población.

ESPERANZA DE VIDA AL NACER (Total población), 2007

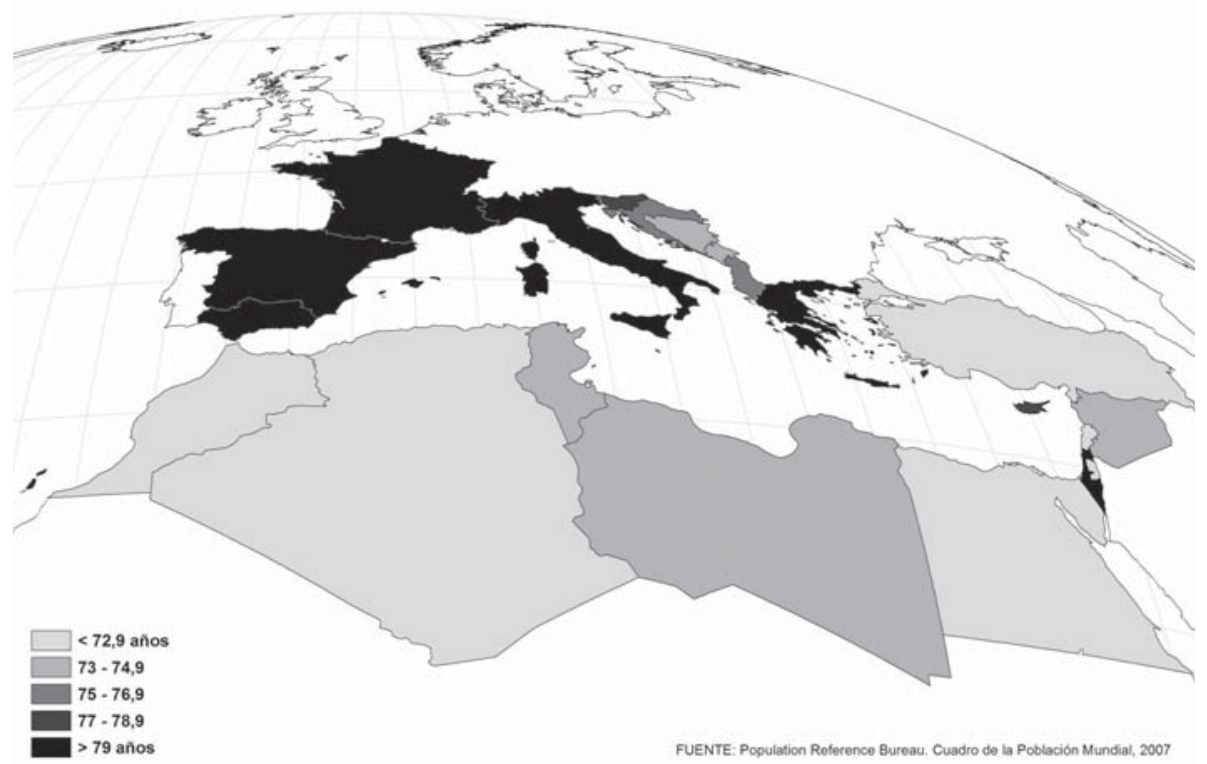

Si diferenciamos por sexos observamos que mientras un bebe que fuera niña y naciera en Francia podría aspirar a vivir 84 años y si fuera niño, 77 , si naciera en Marruecos, no viviría más de 72 y 68 años, respectivamente. 
Un buen modo de concluir y de sintetizar gran parte de lo dicho es acudir a la teoría de la transición demográfica que nos ayuda a tipificar tres estadios en el conjunto mediterráneo:

- El conformado por países en plena fase expansiva, debido al mantenimiento de altos niveles de fecundidad y al retroceso de la mortalidad, como es el caso de Palestina o Siria.

- Países que están finalizando el periodo de transición caracterizados por una natalidad a la baja que converge con una mortalidad que se mantiene en niveles bajos, caso de Turquía, Egipto, Marruecos, Argelia, Albania, Libia y Chipre.

- Países en situación postransicional en los que una fecundidad bajo mínimos contrasta con una mortalidad en auge debido al envejecimiento de la población. Aquí está la práctica totalidad de la orilla europea y, por tanto, Andalucía que bajo este aspecto se integra plenamente en la misma.

El otro componente de la dinámica demográfica es la movilidad migratoria cuestión que en este caso solo vamos a abordar de pasada porque se analiza con detalle en otros artículos. Sintetizando bastante, dentro de las migraciones se podrían diferenciar al menos dos tipos:

Las internas, caracterizadas en la mayor parte del ámbito por el trasvase continúo de población del campo a la ciudad y la consecuente desectructuración de las economías rurales.

En la orilla europea, y especialmente en Andalucía, este fenómeno tuvo su momento álgido en las décadas de los 60 y 70 del siglo pasado. En la margen sur, sin embargo, continúa siendo un fenómeno destacado, especialmente en países como Marruecos, donde la población rural aún es elevada.

La merma del éxodo rural en muchos países ha dado paso a otro fenómeno de relocalización que está conformando un nuevo modelo en el poblamiento, el de las 
aglomeraciones urbanas que está provocando en muchos países miles de cambios residenciales de corto radio en los últimos años.

Por lo que respecta a las migraciones exteriores, la movilidad se ha acentuado considerablemente en las últimas décadas dibujando un panorama complejo en el que, no por puntuales dejan de tener importancia los desplazamientos debidos a cuestiones políticas o a situaciones de conflicto (Balcanes, Grecia-Turquía, IsraelPalestina) que, en determinados momentos, han provocado desplazamientos masivos de población.

Sin embargo, el enorme diferencial económico entre norte y sur hace que las perspectivas de mejora de vida sean el principal motivo de los flujos migratorios en la cuenca mediterránea, donde la orilla europea actúa de receptora, mientras el sur adopta el papel de foco emisor generándose flujos de notable magnitud como los de marroquíes hacia España, los de argelinos a Francia o los de turcos a Alemania.

En cada una de las orillas se pueden encontrar excepciones que rompen la direccionalidad norte-sur de estos flujos, un claro ejemplo es la corriente continua de albaneses a Italia, la emigración de egipcios, tunecinos o argelinos hacia Libia, o el problema de los refugiados palestinos en Siria, Líbano o Egipto.

Este poder de atracción del norte sobre el sur ha establecido, durante décadas, una zona de contacto e intercambio puesta en entredicho a partir del momento en que el flanco norte intenta blindarse para evitar la inmigración masiva y la cada vez más frecuente penetración de flujos clandestinos promovidos por mafias sin escrúpulos que anualmente ponen en peligro la vida de miles de personas subiéndolas en pateras, cayucos o similares y dirigiéndolas hacia un paraíso que muchas veces es difícil encontrar.

Por desgracia este fenómeno, que en Andalucía no nos es ajeno, pues conocemos su peor cara, nos ha convertido en muy poco tiempo en tierra de acogida cuando no hace mucho cientos de miles de andaluces se veían obligados a emigrar para buscar el sustento. 


\section{LA ESTRUCTURA DEMOGRÁFICA.}

Las estructuras por sexo y edad de la población revelan también grandes diferencias entre los distintos sectores de la cuenca mediterránea.

Respecto al género se observa que, a diferencia de lo que ocurre en el lado europeo, donde el número de mujeres es mayor que el de hombres, la sex ratio en la orilla sur es favorable a los varones, hecho que puede resultar extraño si tenemos en cuenta que, aunque nacen más varones que mujeres, la sobremortalidad masculina es mayor a todas las edades y especialmente en las más avanzadas.

Gráfico 9. Evolución de la Sex Ratio en la Cuenca mediterránea

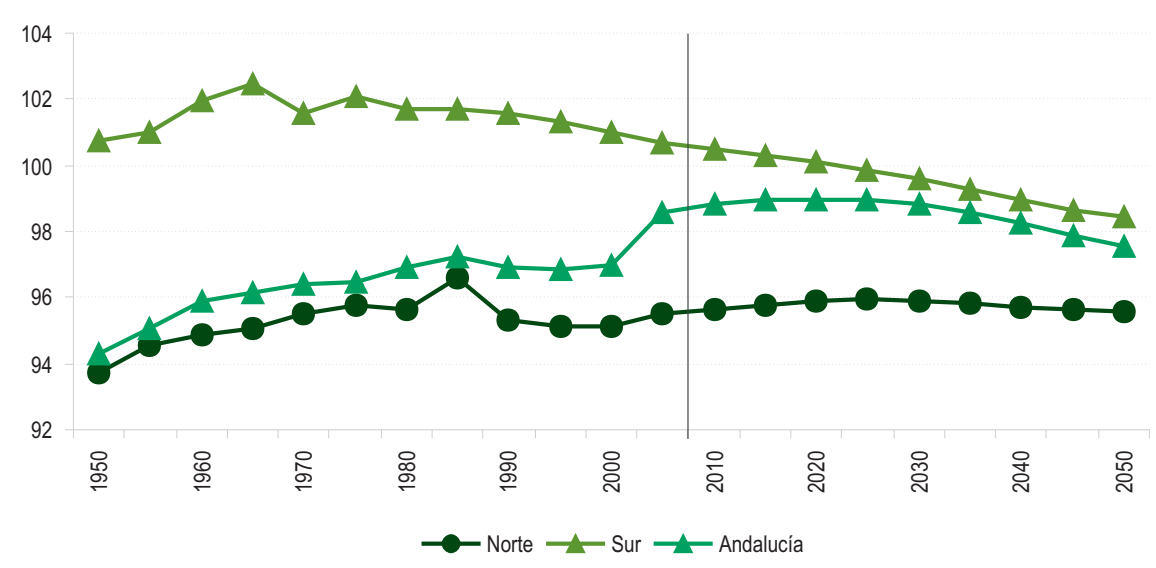

Fuente: Naciones Unidas. Banco de datos de información sobre población.

El porque de este fenómeno puede deberse a razones como el mantenimiento de una desigual movilidad migratoria protagonizada por la mujer, la persistencia de una elevada mortalidad ligada a la maternidad o el subregistro de la mujer en las estadísticas, cuestión esta última para nada infrecuente en muchos países, donde el papel de la mujer se ve muy lastrado por factores religiosos. 
En Andalucía se observa como en la proyección hecha por el Instituto de Estadística de Andalucía la inmigración, mayoritariamente masculina, provoca un reequilibrio entre géneros que hace que el predominio femenino tienda a atenuarse.

En lo que atañe a la edad, el rasgo más llamativo es el progresivo envejecimiento de la población, aunque en este caso el fenómeno es mucho más acusado en la orilla europea donde la edad media de la población se acerca actualmente a los 40,3 años (38 en Andalucía) que en el flanco sur donde se sitúa en torno a los 27,3.

Gráfico 10. Evolución de la edad media de la población en la Cuenca mediterránea

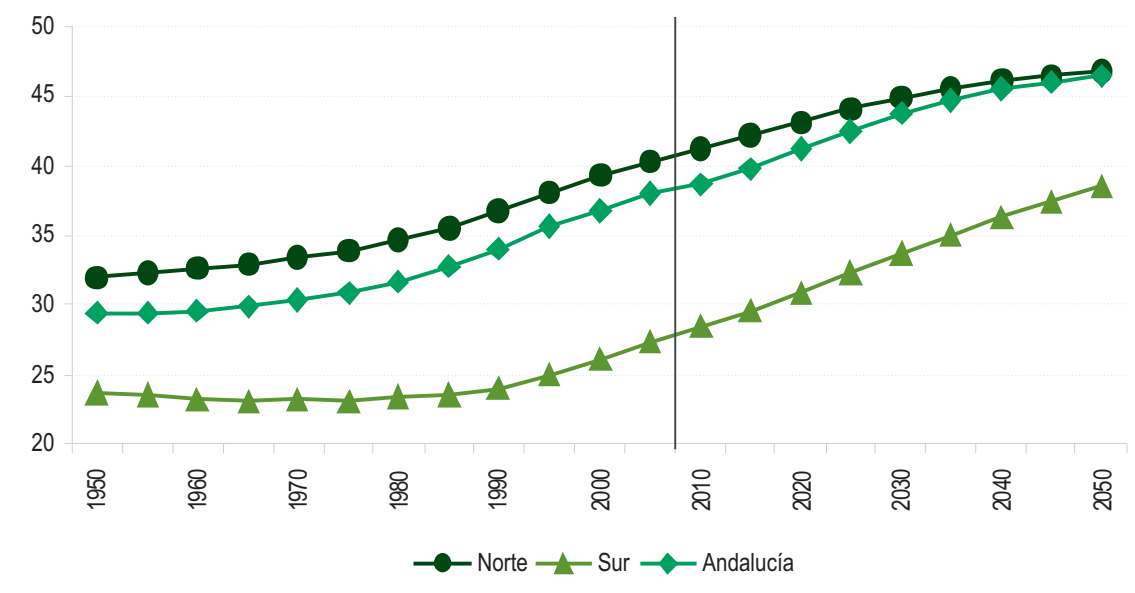

Fuente: Naciones Unidas. Banco de datos de información sobre población.

Observando la evolución de la población por grandes grupos de edad descubrimos que el proceso de envejecimiento antes comentado es doble pues afecta tanto a la base de la estructura etaria, cada vez hay menos jóvenes, como a la cúspide pues cada vez hay más ancianos. 
Gráfico 11. Evolución de la población por grandes grupos de edad en la Cuenca mediterránea

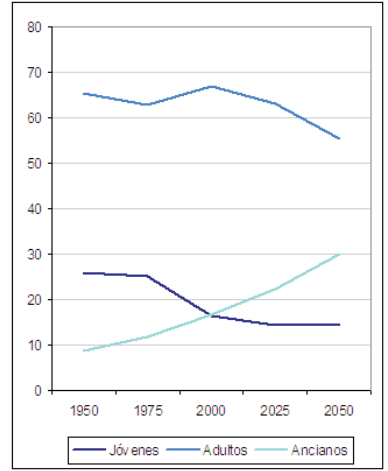

ORILLA NORTE

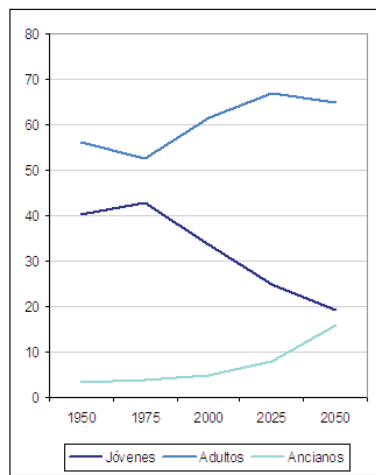

ORILLA SUR

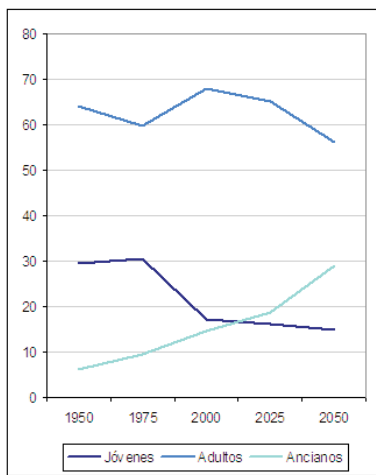

ANDALUCÍA

Fuente: Naciones Unidas. Banco de datos de información sobre población.

La principal diferencia entre ambas orillas apunta al cuerpo central de la estructura de edades pues mientras en el lado europeo el número de adultos tiende a decrecer a favor de los ancianos, en la orilla sur el número de adultos muestra una tendencia alcista que tan solo empezará a frenarse a partir de 2025, lo cual supone un riesgo pues este es el colectivo más propenso a la movilidad migratoria.

Gráfico 12. Pirámides población de la Cuenca mediterránea, 2005

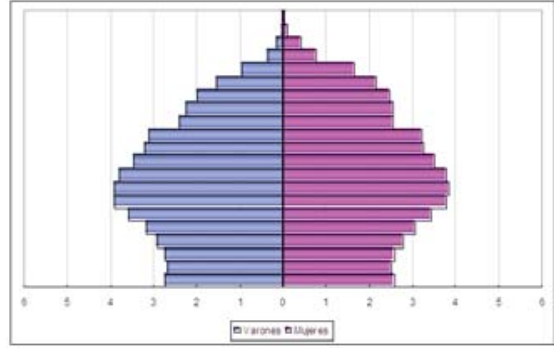

ORILLA NORTE

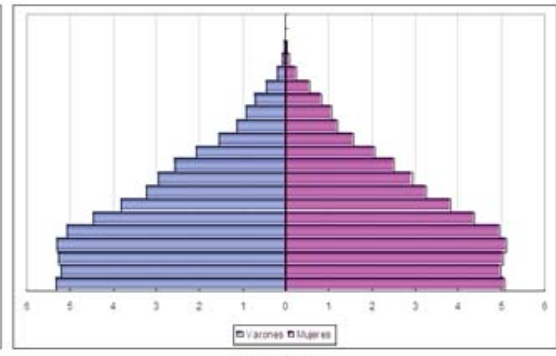

ORILLA SUR

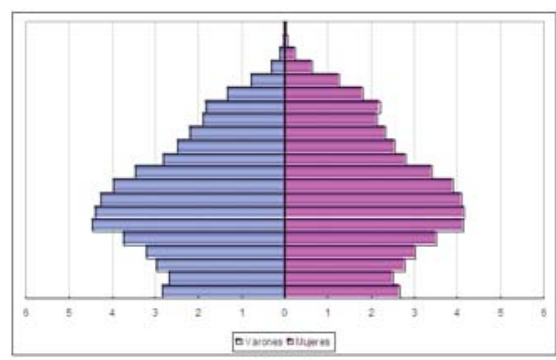

ANDALUCIA

Fuente: Naciones Unidas. Banco de datos de información sobre población. 
Todos los desequilibrios antes apuntados se reflejan claramente en las pirámides de población. De su comparación se pueden destacar como aspectos relevantes la gran diferencia entre ambas fachadas del Mediterráneo. Así, mientras la pirámide del lado europeo muestra una silueta bulbosa, la del lado sur tiene forma de campana. Pese a ello, presentan algunos rasgos comunes, aunque no coincidentes en el tiempo, como la constatación de periodos expansivos apreciables con las partes más anchas de las pirámides, situadas en el cuerpo central de la pirámide europea y más cercanos a la base en la correspondiente a la orilla sur, el retroceso de la fecundidad o la clara tendencia al envejecimiento.

Otro rasgo digno de mención es el agotamiento demográfico de la fachada europea frente al enorme potencial poblacional de la orilla sur pues, pese al retroceso de la fecundidad, la estructura de edades se ve reforzada en su cuerpo central y con ello la capacidad de generación de familias y el mantenimiento de los niveles de crecimiento.

Por lo que respecta a la pirámide andaluza, las similitudes con el caso europeo son mayores que las que se pueden establecer con la silueta de la orilla sur. Tan solo apuntar que se observa cierto retraso en algunos aspectos: baby boom más tardío, menor grado de envejecimiento, posterior recorte de la fecundidad, etc.

\section{ANDALUCÍA ¿FRONTERA DEMOGRÁFICA?. ALGUNOS CONTRASTES CON EL VECINO DEL SUR.}

Separados por los apenas 14 kilómetros del Estrecho de Gibraltar, Andalucía y el Norte de Marruecos ejemplifican, quizá mejor que cualquier otra parte del mundo, lo que podría ser una "frontera demográfica", un espacio donde se observan diferencias de forma tan clara que, sin muchos titubeos, se podría trazar una línea de separación, en este caso entre dos realidades demográficas.

La plasmación cartográfica de algunos indicadores es clave para ello, aunque en el caso concreto del Estrecho lo mismo que hay notables divergencias en la dinámica demográfica o en lo referente a la estructura de la población, también hay algunas similitudes, como las que se observan en relación a la distribución de la población en el territorio. 


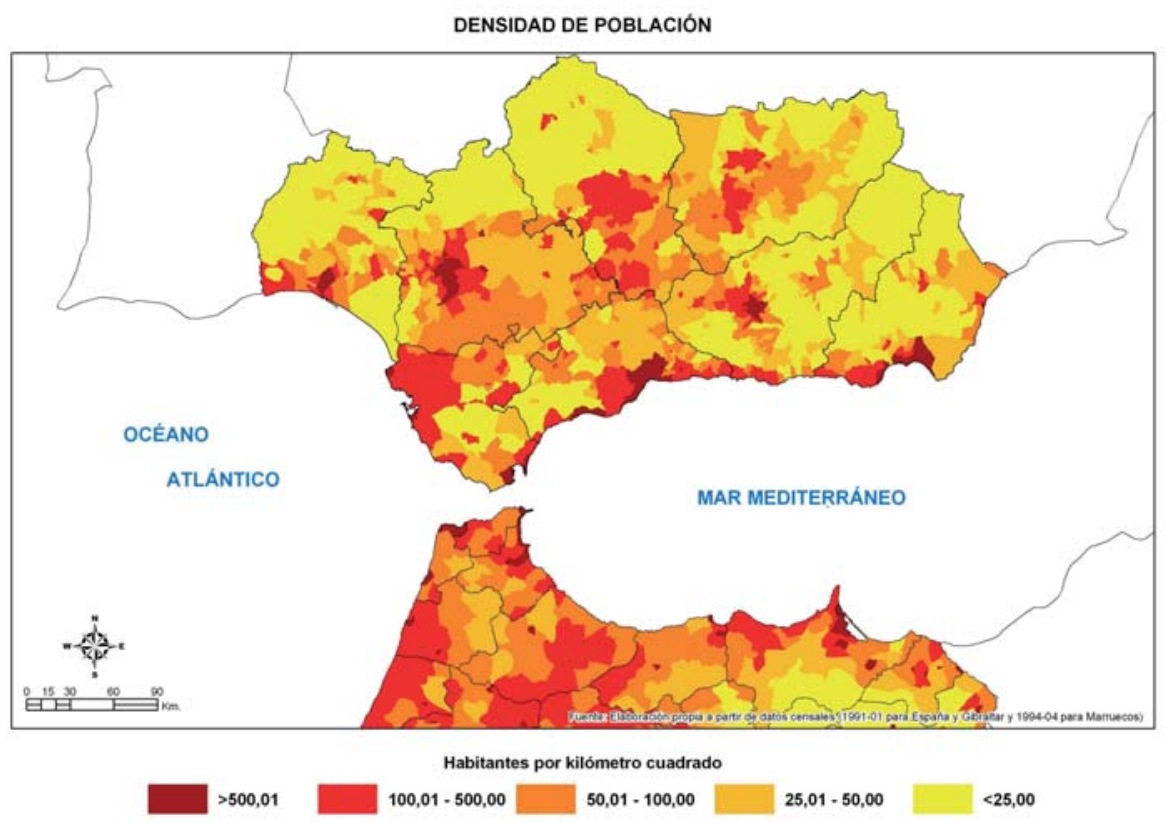

Respecto a la densidad de población, la cartografía elaborada descubre un mayor grado de ocupación en el lado marroquí que en el andaluz. Así mientras el promedio de las nueve provincias/prefecturas marroquíes que nos han servido de referencia en este aparatado ${ }^{5}$, se sitúa próximo a los $180 \mathrm{~h} / \mathrm{Km}^{2}$, configurando una de las zonas más densamente pobladas de Marruecos, en Andalucía la densidad poblacional media se sitúa en la mitad $\left(90 \mathrm{~h} / \mathrm{Km}^{2}\right)$.

También se aprecia, en el norte marroquí, un reparto más equilibrado de la población sobre el territorio ya que en Andalucía se observa una clara polarización tanto hacia las ciudades como hacia el litoral y la existencia de zonas débilmente pobladas coincidentes con los espacios serranos, muy afectados antaño por el éxodo rural. Aunque este es un fenómeno que afecta actualmente al agro marroquí, su incidencia aún no se ha traducido en la concreción de grandes vacíos, al menos en esta zona del país.

\footnotetext{
${ }^{5}$ Las provincias de referencia son Kenitra, Larache, Tánger-Asilah, Fhas Anjra, Tetuan, Chefchaouen, Al Hoceima, Nador y Berkane.
} 


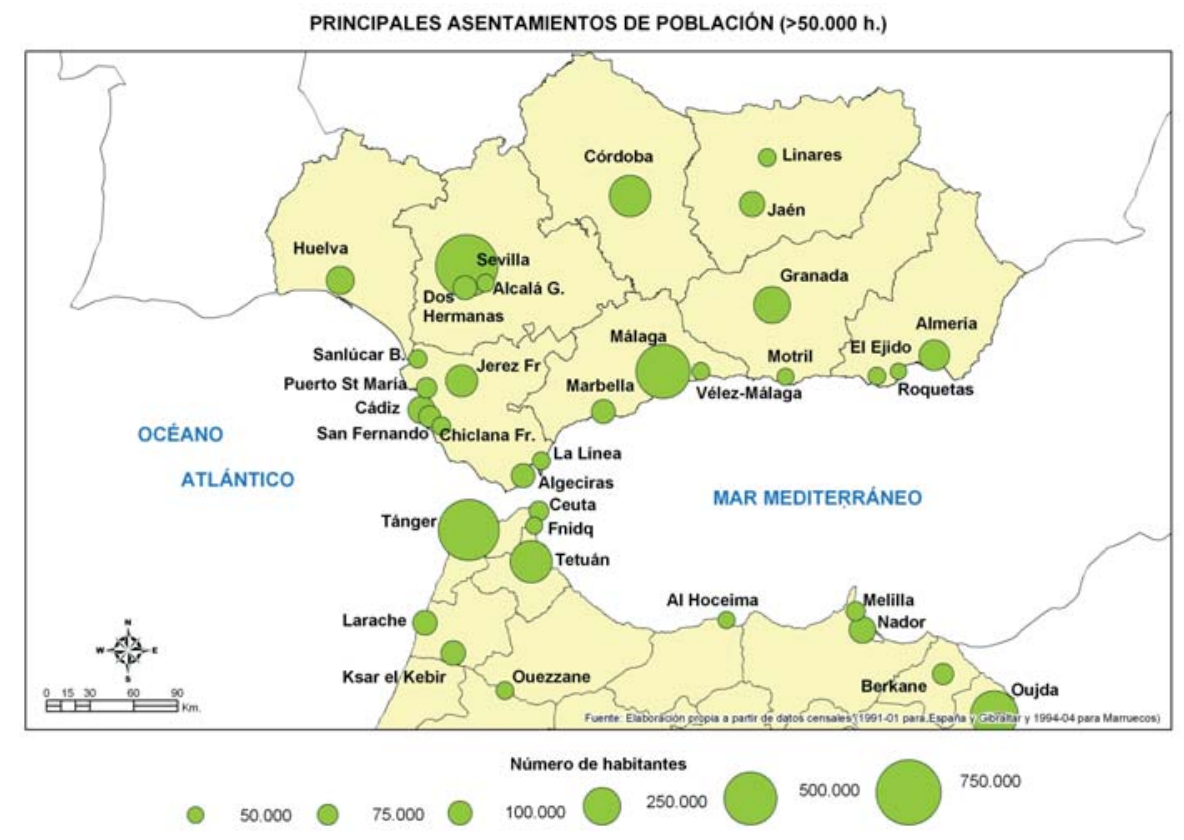

En cuanto a la red de asentamientos principales, cabe decir que la paridad que se aprecia en cuanto a tamaños, se pierde bajo el punto de vista de la distribución territorial pues, si bien es cierto que se observa un fuerte protagonismo del litoral hacia donde se escoran las mayores aglomeraciones urbanas (Tánger, Tetuán, Málaga, Cádiz-Jerez), en el caso andaluz el equilibrio es algo mayor por el contrapeso que supone la existencia de grandes ciudades en el interior (Sevilla, Granada, Córdoba, Jaén) cosa que en la orilla marroquí no ocurre. 


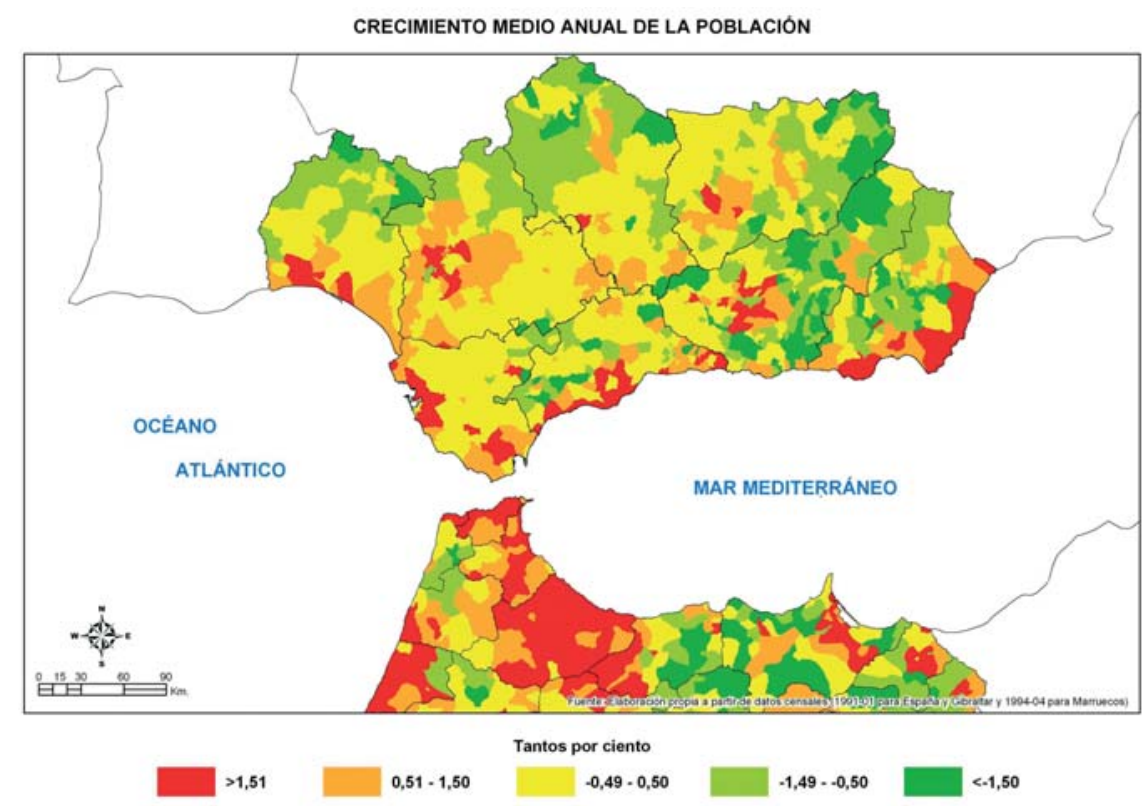

El crecimiento de la población refleja igualmente situaciones contrastadas pues la componente urbano-litoral en la dinámica de crecimiento es más patente en Andalucía que en el caso marroquí, donde provincias eminentemente rurales, como puede ser el caso de Chefchauen, se caracterizan por ser de las de mayor crecimiento demográfico. Las causas de este considerable aumento poblacional se deben, además de a una estructura de población joven, a la atracción que para miles de personas suponen las economías ligadas al cultivo del cannabis.

Por su parte el estancamiento demográfico, situación bastante infrecuente en el lado marroquí (interior de la península tingitana, Rif oriental, etc) predomina en la mayor parte de Andalucía, siendo la tendencia más frecuente en el interior de la región.

Frente a ello, los mayores decrementos demográficos tienen como escenario, por norma general, las zonas de relieve más accidentado, ocurre así tanto en Andalucía (Sierra Morena, Cordilleras Béticas y Penibéticas) como en el Rif Oriental, aunque por razones bien distintas: el sobreenvejecimiento de la población en el 
primer caso, y la emigración masiva en el segundo, siendo las provincias de Nador, Al Hoceima y Berkane algunas de las más afectadas por este fenómeno en el reino de Marruecos.

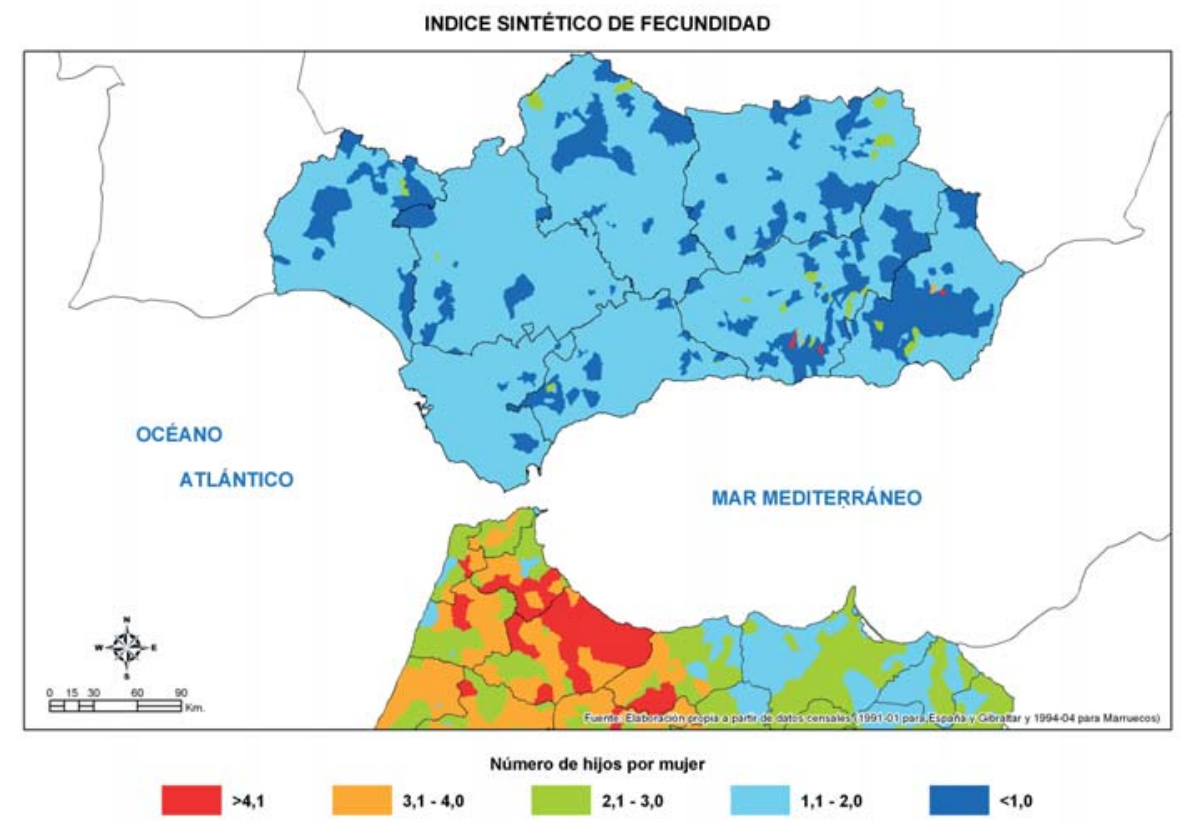

Uno de los indicadores que de forma más clara ponen en evidencia las diferencias entre ambas orillas es el Índice Sintético de Fecundidad que, como se puede apreciar, dibuja dos realidades completamente distintas, la que tiene lugar en Andalucía donde la fecundidad se sitúa claramente bajo los niveles de reemplazo, existiendo zonas en el interior donde apenas se alcanza el hijo por mujer, y la que acontece en el norte marroquí donde la ratio es mucho más elevada y da pruebas de un gran vigor demográfico, especialmente en provincias como Chechauen o Tetuán. Por el contrario, en el Rif Oriental, algunas zonas de las provincias de Nador, Al Hoceima o Berkane ya empiezan a acusar los estragos de la emigración sobre la pirámide de población ya que los colectivos más afectados por el fenómeno migratorio son los grupos en edad de procrear con la consecuente merma en el Índice Sintético de Fecundidad. 


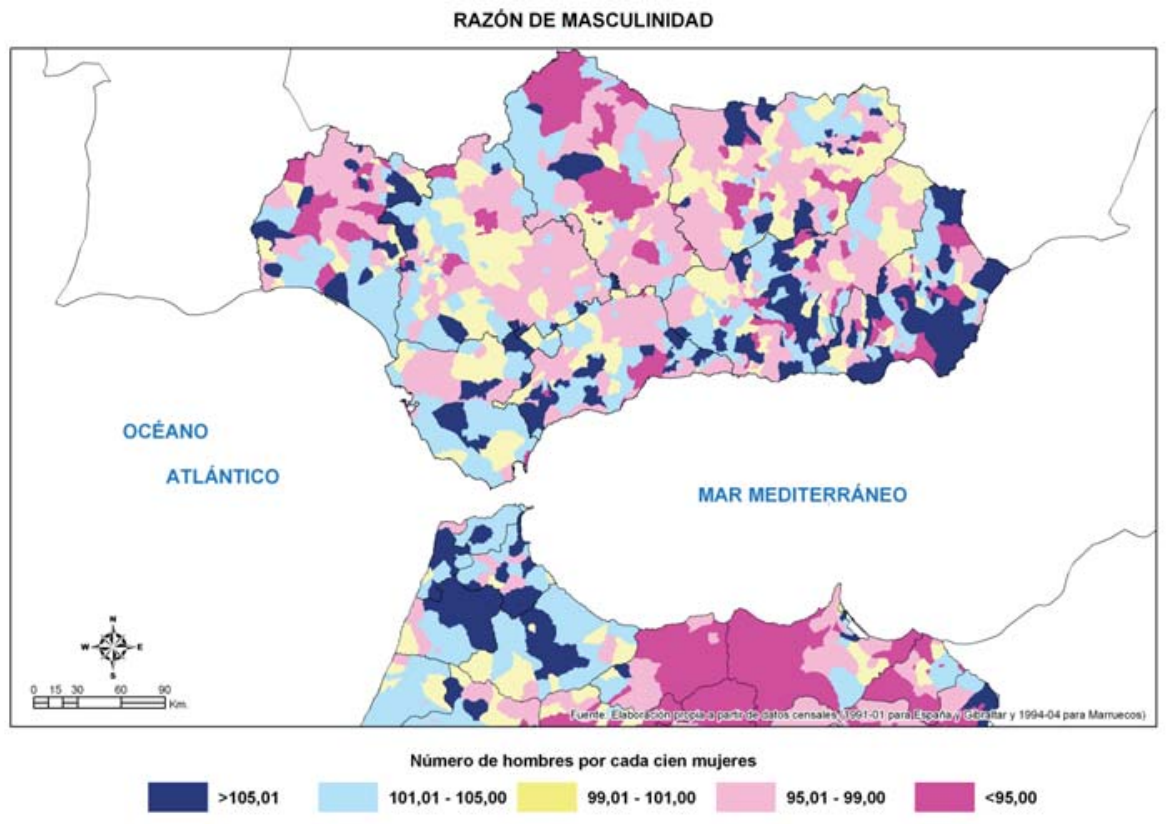

Haciendo abstracción de las situaciones extremas (menos de 95 hombres por cada 100 mujeres o más de 105 varones por cada 100 mujeres) la tónica predominante en el norte de Marruecos, al respecto de la distribución por géneros de la población, es a un desequilibrio de la balanza a favor del sexo masculino, así se observa en la península tingitana, mientras que en la otra orilla, como se aprecia en gran parte del territorio andaluz, ocurre al contrario pues la sex ratio suele ser favorable a las mujeres.

Las situaciones extremas responden a episodios donde otros factores demográficos provocan desequilibrios. En este sentido las migraciones los acentúan considerablemente y de ello el Estrecho puede ser un ejemplo paradigmático. Basta, para darse cuenta, centrar la atención en tres ámbitos: el levante almeriense, como foco de atracción de población inmigrante, predominantemente masculina y en buena medida del norte de África; el interior de la península tingitana como colector 
y trampolín de flujos procedentes de todo Marruecos y del África Subsahariana hacia Europa; y el Rif Central como área de expulsión protagonista de una emigración, acusadamente desigual en lo referente al género, que se traduce en un notable predominio del colectivo femenino.

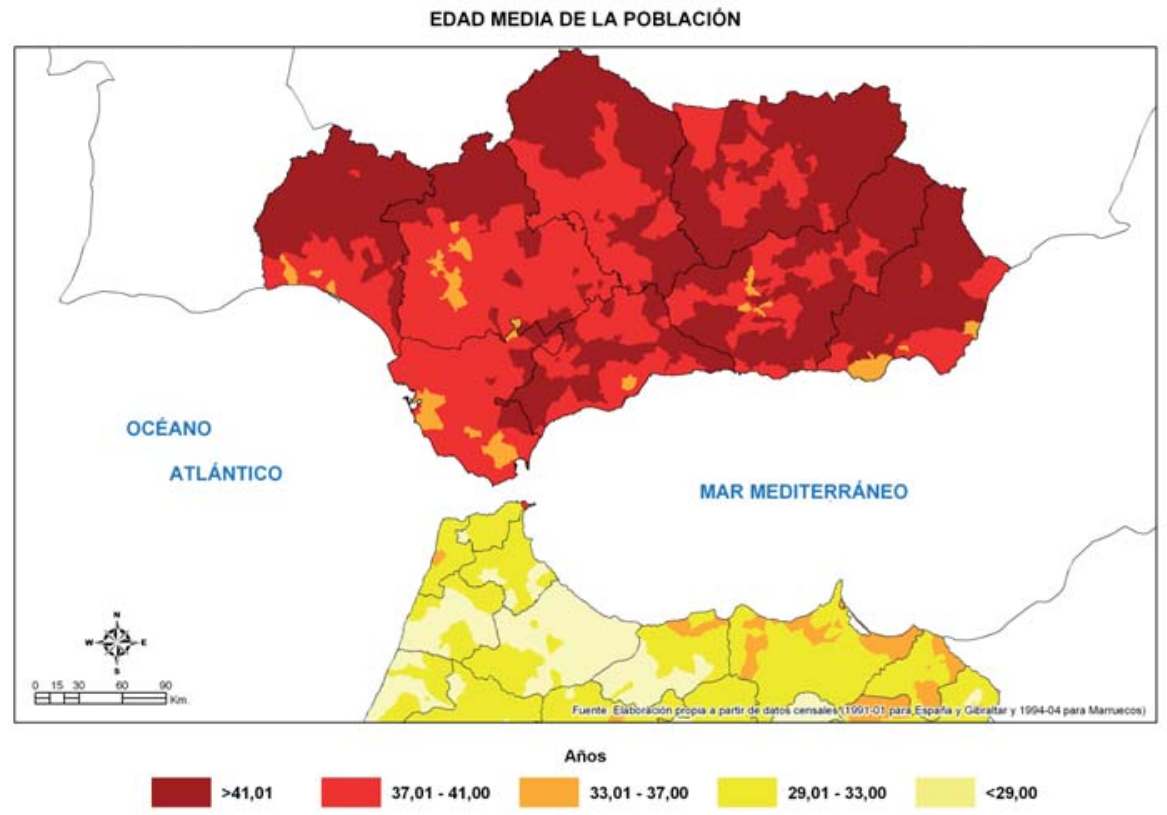

La edad, en este caso la media de edad de la población, es otro de los indicadores que de forma más diáfana muestra la falla demográfica existente entre ambas orillas confrontando una situación de envejecimiento en el lado andaluz frente a la de una población joven en el norte marroquí donde el promedio de edad en algunas comunas de Chefchaouen, Larache o Al Hoceima no llega a los 29 años mientras en muchos de los ámbitos serranos de Andalucía este valor supera los 41 años.

Esto nos lleva a la necesidad de arbitrar políticas muy distintas en una y otra ribera pues mientras en el norte deberían ir enfocadas a resolver problemas ligados al bienestar de la población mayor, en el sur habría que incidir en cuestiones como la formación o una mayor y mejor accesibilidad de la población al mercado laboral. 


\section{CONCLUSIONES.}

Como se ha podido apreciar, a lo largo de los diferentes apartados, Andalucía se inserta plenamente en la dinámica de la orilla europea haciéndolo, según todos los indicadores, tras un periodo de convergencia al que ha llegado tarde y quemando etapas muy rápidamente.

En este contexto, el cambio más radical ha sido, quizá, la conversión en zona receptora de inmigración cuando durante décadas los flujos migratorios habían sido negativos.

Por lo demás, los indicadores apuntan a esa fase postransicional típica del resto de países europeos y, caracterizada por un acusado envejecimiento y un leve repunte de la fecundidad y por la ruptura del modelo de familia tradicional y la adopción de nuevos estilos de vida.

Frente a ello, la orilla sur presenta un panorama muy distinto marcado por un fuerte crecimiento que, pese al recorte de la fecundidad, amenaza al norte con una marea migratoria sin precedentes si no se toman las medidas adecuadas. Otro de los riesgos es la acentuación de los desequilibrios territoriales, económicos, sociales, etc y el reforzamiento de la "frontera demográfica" existente, situación que confiere a la población el papel de bomba de relojería que continuamente amenaza con estallar.

Las cosas no son, sin embargo, tan simples como para que la oposición norte sur se pueda reducir a la coexistencia de dos modelos distintos en la cuenca mediterránea, la realidad es mucho más compleja y cada país o zona tiene sus propias dinámicas y especificidades.

Lo que si parece cierto es que, pese a ello, las tendencias, en un horizonte de futuro a medio-largo plazo, apuntan a un proceso de convergencia, aunque aún queda mucho camino por recorrer.

La principal conclusión que se puede extraer de un Mediterráneo como "frontera demográfica" y de Andalucía como parte implicada es que, como afirma el profesor Khader: "el Mediterráneo es demasiado estrecho para separar y demasiado ancho para confundir". 


\section{BIBLIOGRAFÍA Y FUENTES UTILIZADAS.}

AA.VV. (2002) El nuevo orden demográfico. El campo de las ciencias y de las artes, 139. Servicios de Estudios BBVA. Madrid.

ATTANÉ, I. y COURBAGE (2004). Demography in the Mediterranean Region. Situation and Projections. Plan Bleu.

BUCCIANTI, C. (2003) Le rive del Mediterraneo: Una demografía in evoluzione. Quaderni del Dipartimento per lo studio delle Società Mediterranee, 26. Cacuccci Editore. Bari.

GOLINI,A.yMARINI,C. (2005) II fattore popolazione nell'area euromediterranea. Una prospettiva lungo il XX e XXI secolo. Quaderni del Dipartimento per lo studio delle Società Mediterranee, 32. Cacuccci Editore. Bari

IEA (2007) Proyección de la población de Andalucía, 2006-70. Sevilla

KHADER, B. (1992). La geopolítica de la demografía mediterránea. Europa frente al sur., 14 y 15. Red Eurosur

NACIONES UNIDAS (2008) Banco de Datos de Información sobre Población de las Naciones Unidas (www.un.org/spanish/popin).

OUADAH-BEDIDI, Z. y VALLIN, J. (2000) Maghreb: la chute irrésistible de la fécondité. Population \& Sociétés, 359. INED. París.

PUYOL, R. (2003) La población en le Mediterráneo en Bejamín Oltra (ed) Sociedad, civilizaciones y culturas. Altea. Fundación de Ciencias Sociales y Mundo Mediterráneo.

UNFPA (2007). Cuadro de la población mundial. Population Referente Bureau. Washington. 